\title{
MULTI-CRITERIA OPTIMIZATION SOFTWARE LEVI-4.0 A TOOL TO SUPPORT DESIGN AND MANAGEMENT IN CONSTRUCTION
}

\author{
Edmundas Kazimieras Zavadskas \\ Vilnius Gediminas Technical University, \\ Sauletekio av. 11, Vilnius, LT-10223, Lithuania, \\ Email: edmundas.zavadskas@adm.vtu.lt
}

\author{
Friedel Peldschus \\ Leipzig University of Applied Sciences, \\ Karl-Liebknecht Street 132, 04277 Leipzig, \\ Germany, \\ Email: peldschu@fbb.htwk-leipzig.de
}

\author{
Zenonas Turskis \\ Vilnius Gediminas Technical University, \\ Sauletekio av. 11, Vilnius, LT-10223, Lithuania, \\ Email: zenonas.turskis@st.vgtu.lt
}

\begin{abstract}
Multi-criteria decision making is used in many areas of human activities. Criteria can to be qualitative and quantitative. They usually have different units of measurement and different optimization direction. The normalization aims at obtaining comparable scales of criteria values. In the new program LEVI 4.0 version the following normalization methods are possible: vector, linear scale, non-linear and new logarithmic techniques. This software considers the main positions of two-sided game problems. The strategic principles are used as follows: Wald's rule, Savage criterion, Hurwicz's rule, Laplace's rule, Bayes's rule, Hodges-Lehmann rule. This program is demonstrated with a real case study involving 4 evaluation criteria of external walls of the individual residential buildings, now in use.
\end{abstract}

\section{KEYWORDS}

Software, of two-sided problem, game theory, normalization, logarithmic, multi-criteria, a wall

\section{INTRODUCTION}

A review of standard decisions made in engineering, management and economy, has shown that the evaluation of all possible actions is not always sufficient. Each action may lead to several, sometimes conflicting results. Therefore, multi-criteria decision making becomes extremely important.
Any problem to be solved is represented by a matrix, containing the alternatives (rows) and the criteria (columns). An alternative in multi-criteria evaluation is usually described by quantitative and qualitative criteria. Usually, the criteria have different dimensions. In order to avoid the difficulties caused by different dimensions of the criteria, the ratio to the optimal value is used. There are various theories 
describing the ratio to the optimal value. However, the values are mapped either on the interval $[0 ; 1]$ or the interval $[0 ; \infty]$ by applying the normalization of a decision-making matrix.

Vilnius Gediminas Technical University (VGTU) and Leipzig University of Applied Sciences (HTKW) have been investigating the application of games theory principles to civil engineering technology and management problems for more than 25 years [1], [2], [3], [4], [5], [6], [7]. The program LEVI 3.0 was a result of the co-operation between VGTU and HTKW. All calculations are made with LEVI 4.0 [3], [4], [8], [9], [10], [11]. The program LEVI 4.0 was modified for evaluating various processes in economics, engineering and management.

In the new program version LEVI 4.0 (Fig. 1 and Table 1) a new logarithmic normalization method [8] is implemented. This new software allows us to find a solution under the conditions of risk and uncertainty and to compare the results by applying different methods.

\section{STRUCTURE AND METHODOLOGY OF THE PROGRAM LEVI 4.0}

In the program LEVI 4.0, the game theory of the discrete optimization problem solution is used.
Using the Games Theory [12], the two-sided question aims at finding the equilibrium as a result of the rational behaviour of two parties having the opposite interests or searching for the equilibrium in a game against nature.

Wald's rule (WA): This method is used to search for the best of the worst solutions [13]. The decision-maker acts according to the worst situation occurring - a pessimistic attitude:

$$
S^{*}=\left\{S_{i} / S_{i} \in S \cap \max _{i} \min _{j} b_{i j}\right\}
$$

Savage criterion (SA): The aim is the minimization of the loss of appropriateness, which is the difference between the greatest and the achieved benefit [14]:

$$
S^{*}=\left\{\begin{array}{l}
S_{i} / S_{i} \in S \\
\cap \min _{i} \max _{j} c_{i j} \\
\cap c_{i j}=\left(\max _{r} a_{r s}\right)-a_{r s}
\end{array}\right\},
$$

where $r=\overline{1, m}$ and $s=\overline{1, n}$. A disadvantage of the method lies in the presence of non-optimal strategies affecting the solution.
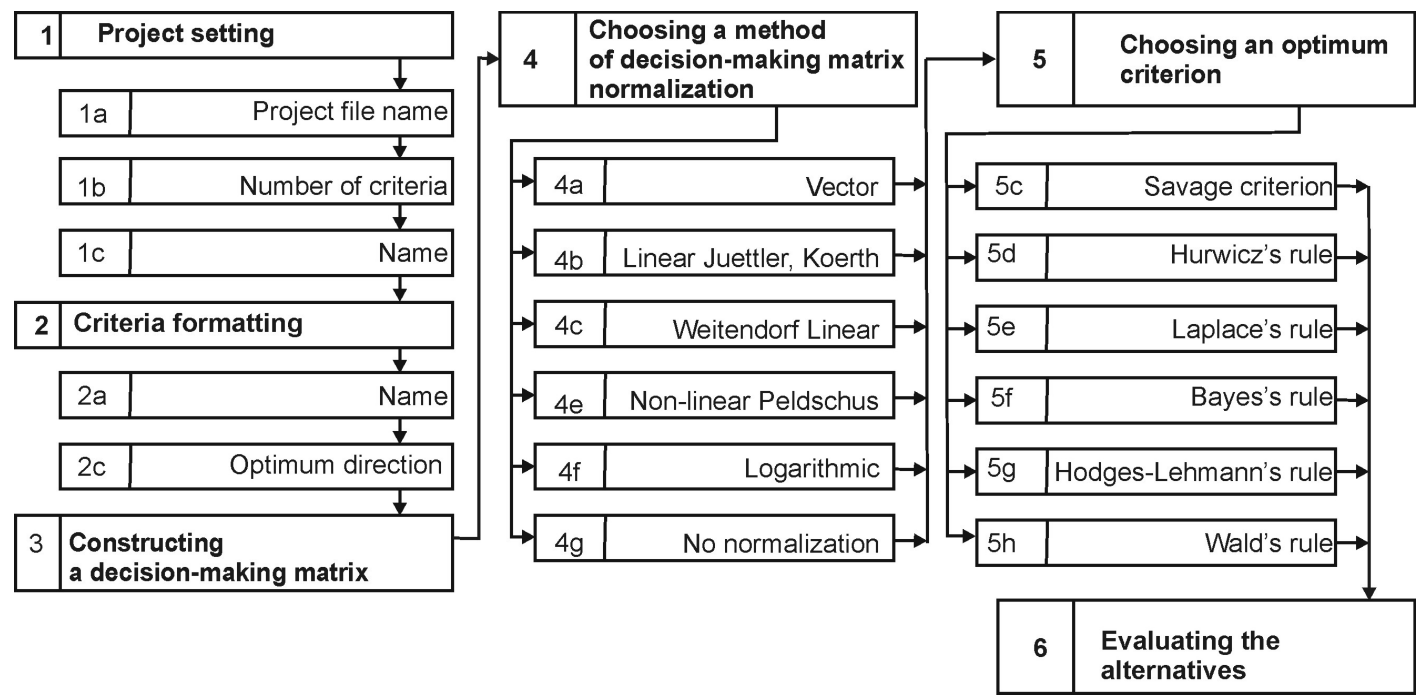

Figure 1. Block-diagram of choosing the best alternative in LEVI 4.0 program 
Table 1. Normalization methods in program LEVI 4.0

\begin{tabular}{|c|c|c|c|c|}
\hline & $\begin{array}{l}\text { Normalization } \\
\text { method (NM) }\end{array}$ & $\begin{array}{l}\text { Preferable } \\
\max a_{i j}\end{array}$ & $\begin{array}{l}\text { Preferable } \\
\min a_{i j}\end{array}$ & Notes \\
\hline 1 & Vector (VE) & $b_{i j}=\frac{a_{i j}}{\sqrt{\sum_{i=1}^{m} a_{i j}^{2}}}$ & $b_{i j}=1-\frac{a_{i j}}{\sqrt{\sum_{i=1}^{m} a_{i j}^{2}}}$ & $\begin{array}{l}\text { The ratio of the values remains constant for this } \\
\text { type of normalization in the interval }[0 ; 1] \text {. }\end{array}$ \\
\hline 2 & $\begin{array}{c}\text { Weitendorf's linear } \\
{[19]} \\
(\mathrm{WL})\end{array}$ & $b_{i j}=\frac{a_{i j}-\min a_{i j}}{\max _{i} a_{i j}-\min a_{i j}}$ & $b_{i j}=\frac{\max _{i} a_{i j}-a_{i j}}{\max _{i} a_{i j}-\min _{i} a_{i j}}$ & $\begin{array}{l}\text { The calculated values are dependent on the size } \\
\text { of the interval }\left[\max _{i} a_{i j} \min _{i} a_{i j}\right\rfloor\end{array}$ \\
\hline 3 & $\begin{array}{l}\text { Jüttler's -Körth's } \\
\text { [20], [21] }\end{array}$ & $b_{i j}=1-\left|\frac{\max a_{i j}-a_{i j}}{i}\right| \frac{\max a_{i j}}{i} \mid$ & 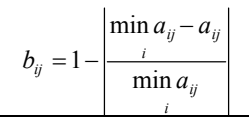 & $\begin{array}{l}\text { The application of this type of normalization is } \\
\text { limited to the interval }[0 ; 1] .\end{array}$ \\
\hline 4 & $\begin{array}{l}\text { Peldschus et al. [1] } \\
\text { non-linear } \\
\text { (NL) }\end{array}$ & $b_{i j}=\left(\frac{a_{i j}}{\max _{i} a_{i j}}\right)$ & $b_{i j}=\left(\frac{\min a_{i j}}{a_{i j}}\right)^{3}$ & $\begin{array}{l}\text { The values are diminished more than when using } \\
\text { other methods }\end{array}$ \\
\hline 5 & $\begin{array}{l}\text { New Logarithmic } \\
\text { (LN) [8] }\end{array}$ & $b_{i j}=\frac{\ln \left(a_{i j}\right)}{\ln \left(\prod_{i=1}^{n} a_{i j}\right)}$ & $b_{i j}=\frac{1-\frac{\ln \left(a_{i j}\right)}{\ln \left(\prod_{i=1}^{n} a_{i j}\right)}}{n-1}$ & $\begin{array}{l}\text { The sum of normalized criterion values is always } \\
\text { equal to } 1 .\end{array}$ \\
\hline
\end{tabular}

Hurwicz's rule (HU): An optimal strategy is based on the best and the worst results [15]. These values, calculated from the row's minimum and row's maximum, are integrated into a weighted average using optimism parameters:

$S^{*}=\left\{\begin{array}{l}S_{i} / S_{i} \in S \cap \max _{i} h_{i} \\ \cap h_{i}=\lambda \max _{j} b_{i j}+(1-\lambda) \min _{j} b_{i j} \\ \cap 0 \leq \lambda \leq 1\end{array}\right\}$.

The value $\lambda=1$ gives the most pessimistic solution (Wald's rule). For the value $\lambda=0$ only the maximum values are considered, the greatest risk.

Laplace's rule (LA): The solution is calculated under the condition that all probabilities for the strategies of the opponent are equal [16]:

$$
S^{*}=\left\{S_{i} / S_{i} \in S \cap \max _{i}\left(1 / n \sum_{i=1}^{n} b_{i j}\right)\right\} \text {. }
$$

Bayes's rule (BA): Given the probabilities for the strategies of the opponent the maximum for the expected value can be used [17]:

$$
S^{*}=\left\{S_{i} / S_{i} \cap \max _{i}\left(\sum_{j=1}^{n} q_{j} b_{i j}\right) \cap \sum_{j=1}^{n} q_{j}=1\right\} .
$$

Hodges-Lehmann rule (HL): According to this rule, the confidence in the knowledge of the probabilities of the strategies of the opponent can be expressed by the parameter $\lambda[18]$ :

$$
S^{*}=\left\{\begin{array}{l}
S_{i} / S_{i} \in S \cap \\
\max _{i}\left[\lambda \sum_{j=1}^{n} q_{j} b_{i j}+(1-\lambda) \min _{j} b_{i j}\right] \cap \\
0 \leq \lambda \leq 1
\end{array}\right\},
$$

where $\lambda=0$ (no confidence) gives the solution according to Wald's rule, while $\lambda=1$ (great confidence) gives the solution according to Bayes's rule.

\section{A CASE STUDY OF EXTERNAL WALL ALTERNATIVES EVALUATION USING VARIOUS SOLUTION METHODS AND NORMALIZATION TECHNIQUES}

The number of residential houses in Lithuania is increasing every year. Introduction of various thermoinsulation systems in the contemporary civil engineering practice is caused by the major expansion 
of energy resource prices at the world market. For a non-insulated building, which could be situated in different climate conditions, these particular heatlosses can vary between 10-20\% (through floors), 25 $30 \%$ (through outer walls), 25-30\% (through attic slabs and roof plates) and 30-40\% (through windows) of the total heat-loss. Therefore, the thorough and professional selection of an optimal building thermoinsulation system represents one of the most important technical and economical goals for both the Designer and the Investor. The benefit obtained from effectively heating up the external walls could be defined by indices as shown in Figure 2.

\subsection{Multi-layered external walls}

There is usually not enough attention paid to the fact that multi-layered facade structures are made as composite sections of heterogeneous materials with different physical-mechanical properties.

For multilayer walls, three basic material configurations were considered: insulation either inside or outside the massive layer, and insulation located between two massive layers. The results of extensive parametric analysis have shown explicitly that walls with the insulation outside (Figure 3) always performed better than those with the insulation inside.

\subsection{Model of problem}

The aim of this investigation is to create a technique for the choice and selection of different and effective versions of the construction of external walls.

Different variants of external wall construction are being formed by using various materials with thermal insulation as well as different kinds of decoration masonry and thin daub layer. A system of indicators for wall construction effectiveness' evaluation has been established. These indicators define positive and negative characteristics of an object under investigation.

Indicator values were calculated according to valid standardizing documents. The selection of a wall construction determines technical, exploitation, etc indicator of a building. One of the most important factors of a wall partition is its aesthetic view; however this factor is not an objective one.

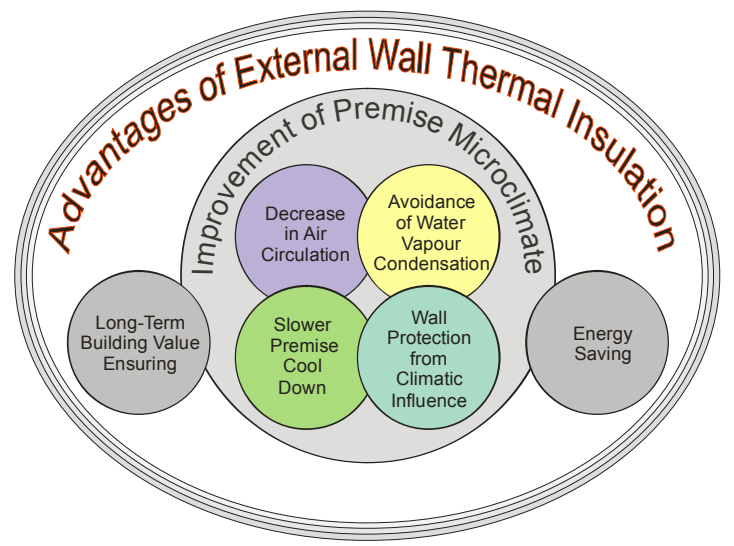

Figure 2. Advantage of thermal insulation of external walls
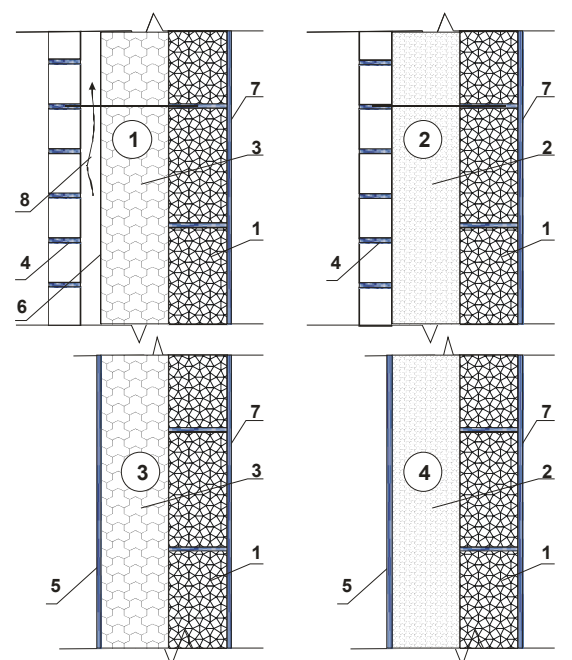

1 - Bearing block;

2 - Expanded

polystyrene;

3 - Rock wool;

4 - Finishing brick;

5 - Outer plaster;

6 - Isolation of the

wind;

7 - Inner plaster;

8 - Air space $(2-3 \mathrm{~cm})$

Figure 3. Main alternatives of multi-layered external walls

The price of partitions is calculated by including all the expenses of materials that a partition is composed of. The price of a three-layer masonry wall embraces the following: silicate bearing walls, thermal and wind insulation, decoration masonry, and grout. The price of walls with thin daub layer consists of: silicate bearing walls, thermal insulation and the price of thin daub layer system. In order to establish the importance 
indicators a survey has been carried out and 39 experts have been questioned. These experts, basing their answers on their knowledge, experience and intuition, had to rate indicators of effectiveness starting with the most important. The rating was done on a scale from 1 to 4 where 4 meant "very important" and 1 "not important at all". The importance of indicators (e.g. 3) was established according to the rating methods [6] of these experts and also demonstrated the priorities of the user (owner).

The data of the external walls' alternatives under investigation are given in Table 2 .

Table 2. The ranked alternatives

\begin{tabular}{|c|c|c|c|}
\hline \multirow{2}{*}{ Var. } & \multicolumn{2}{|c|}{ Description of wall } & \multirow{2}{*}{ Rank } \\
\cline { 2 - 3 } & Finishing material & Thermal & \\
\hline$v_{l}$ & Brick & Rock wool & 3 \\
\hline$v_{2}$ & Brick & Polystyrene & 1 \\
\hline$v_{3}$ & Thin external & Rock wool & 4 \\
\hline$v_{4}$ & Thin external & Polystyrene & 2 \\
\hline
\end{tabular}

There is a wide variety of external wall constructions which are defined by many different indicators of effectiveness (A closer look at the most commonly used outer-wall building systems is given in figure 3). According to opinion of building experts, these alternatives of walls can be characterized by following factors as shown in table 2. Efficiency of the variant was evaluated by the following effectiveness indices: estimated cost of $\mathrm{m}^{2}$ $(€)$, weight of $\mathrm{m}^{2}(\mathrm{~kg})$, thermal insulation $\left(\mathrm{m}^{2} \mathrm{~K} / \mathrm{W}\right)$ and durability of walls (cycles).

The task of the selection of different versions of the effective external walls construction is solved by applying LEVI 4.0 software.

A special feature of the model is the determination of attributes weights [22]. To determine the weights of the criteria, the expert judgment method proposed by Kendall [23] was used [24]. Zavadskas [6] discussed the application of this method in the construction field.

In the present investigation, the vector, linear, nonlinear and new logarithmic methods of initial decision-making matrix normalization were used. A number of different problem solution methods, such as Wald's rule, Savage criterion, also Laplace's rule, and Bayes's rule were applied. Tables 4 and 5 provide the solution results and comparative analysis. When the criteria weights are taken into account, the priority order of the alternatives is presented as " $v_{2} \succ v_{1} \succ v_{3} \succ v_{4}$ " (implying that the "second" alternative is better than the "first" one, the "first" alternative is better than the "third" one, the "third" alternative is better than the "second" one and the "fourth" one). A similar set " $v_{2} \succ v_{1}=v_{4} \succ v_{3}$ " is obtained when the criteria weights are not taken into account in the process of alternative assessment. Finally alternatives ranks $v_{2} \succ v_{4} \succ v_{1} \succ v_{3}$ and are presented in table 6 .

Under analysis of the problem decision results it has been established, that wall with a brick external layer are the most effective. Furthermore, it is possible to ascertain, that application of a $175 \mathrm{~mm}$ layer of rock wool more effectively than application of a $200 \mathrm{~mm}$ layer of Polystyrene.

\section{CONCLUSION}

It is hardly possible to evaluate the effect of various methods of normalization of a decision-making matrix on the numerical results obtained. These problems can be solved by applying the program LEVI 4.0.

Some modules of the program LEVI 4.0 can be used for creating decision-making systems.

Logarithmic normalization of a decision making matrix yields more stable results in solving multicriteria decision problems.

The logarithmic normalization method used in solving the problems segregates more normalized values than the other ones.

A comparison of results obtained by different solution methods is needed because it is not always possible to apply the games theory equilibrium to economics, engineering and management. It can be stated that:

1. The multiple attribute assessment model of multi-layer external walls was developed.

2. This model and solution results has as practical as scientific interest. It allows to investor to make decision evaluating multiple criteria. 
3. Walls with a brick external layer are the most effective.

4. This model of the external walls efficiency analysis of can be applied to the assessment others discrete alternatives problem in construction.

\section{REFERENCES}

[1] Peldschus, F., Vaigauskas, E. and Zavadskas, E.K. (1983). Technologische Entscheidungen bei der Berücksichtigung mehrerer Ziehle. BauplanungBautechnik, Vol. 37, No. 4 173-175.

[2] Peldschus, F. (1986). Zur Anwendung der Theorie der Spiele für Aufgaben der Bautechnologie. Diss. B. Technologie. Diss. B. Technische Hochschule Leipzig.

[3] Peldschus, F., Messing, D., Zavadskas, E.K., Ustinovichius, L. and Turskis, Z. (2002). LEVI $3.0-$ multiple criteria evaluation program under uncertainty. Technological and Economic Development of Economy, Vol. 8, No. 13 - 12.

[4] Peldschus, F. (2007). The effectiveness of assessment in multiple criteria decisions. International Journal of Management and Decision Making, Vol. 8, Nos. 5-6 519-526.

[5] Peldschus, F., and Zavadskas, E.K. (1997). Matrix games in building technology and management. Vilnius: Technika. (In Lithuanian)

[6] Zavadskas, E.K. (1987). Multiple criteria evaluation of technological decisions of construction. Dissertation of Dr. Sc. Moscow Civil Engineering Institute, Moscow. (In Russian).

[7] Turskis, Z., Zavadskas, E. K., Zagorskas, J. (2006). Sustainable city compactness evaluation of the basis of GIS and Bayes rule. International Journal of Strategic Property Management, Vol. 10, No. 3 185207.

[8] Zavadskas, E.K., and Turskis, Z. (2008). A new normalization method in games theory, Informatica, Vol. 19, Article in press.

[9] Zavadskas, E.K., Ustinovichius, L., Turskis, Z., Peldschus, F. and Messing, D. (2002). LEVI $3.0-$ Multiple criteria evaluation program for construction solutions. Journal of Civil Engineering and Management, Vol. 8, No. 3 184-191.

[10] Zavadskas, E.K., Peldschus, F., Ustinovichius, L. (2003). Development of software for multiple criteria evaluation. Informatica, Vol. 14, No. 2, 259-272.
[11] Zavadskas, E.K., F. Peldschus, Ustinovichius, L. and Turskis, Z. (2004). Game theory in building technology and management. Vilnius: Technika. (In Lithuanian)

[12] Neumann von, J. and Morgenstern, O. (1943). Theory of Games and Economic Behavior. Princeton University Press.

[13] Wald, A. (1945). Statistical decisions functions which minimise the maximum risk. Annals of Mathematics, Vol. 46 265-280.

[14] Savage, L. J. (1951). The Theory of Statistical Decision. Journal of the American Statistical Association, Vol. 46 55-57.

[15] Hurwicz, L. (1951). Optimality Criteria for Decision Making under Ignorance. Cowles Commission Paper, Statistics, Vol. 370 45-52.

[16] Bernoulli, D. (1738). Specimen theoriae novas de mesure sortis. Comentarii Academiae Scientarium Inperialis Petropolitanae, Vol. 5 175-192. (Translated by Sommer L. (1954) Exposition of a new theory on the measurement of risk, Econometrica, Vol. 22 23-36.

[17] Arrow, K.J., Blackwell, D. and Girshick, M. A. (1949). Bayes and Minimax Solutions of Sequential Decision Problems. Econometrica, Vol. 17 213-243.

[18] Hodges, J.L., and. Lehmann, E.L (1952). The Use of Previous Experience in Reaching Statistical Decision. Annals of Mathematics Studies, Vol. 23 396-407.

[19] Weitendorf, D. (1976). Beitrag zur Optimierung der räumlichen Struktur eines Gebäudes. Dissertation A, Hochschule für Architektur und Bauwesen. Weimar.

[20] Jüttler, H. (1966). Untersuchungen zur Fragen der Operations aforschung und ihrer Anwendungsmöglichkeiten auf ökonomische Problemstellungen unter besonderer Berücksichtigung der Spieltheorie, Dissertation A an der Wirtschaftswissenschaftlichen Fakultät der Humboldt - Universität, Berlin.

[21] Körth, H. (1969). Zur Berücksichtigung mehrer Zielfunktionen bei der Optimierung von Produktionsplanen. Mathematik und Wirtschaft, Vol. 6 184-201

[22] Hwang, C.L., and Yoon, K.P (1981). Multiple Attribute Decision Making - Methods and Applications. New York: Springer-Verlag.

[23] Kendall, M.G. (1970). Rank correlation methods (4th ed.), London, Griffin.

[24] Fisher, R.A. and Yates, F. (1963). Statistical tables for biological, agricultural and medical research (6th ed), Oliver and Boyd, London. 